\title{
The Role of Natural Killer (NK) Cells in Experimental Autoimmune Encephalomyelitis (EAE) and Multiple Sclerosis (MS)
}

\author{
Wen $\mathrm{Xu}^{\mathrm{a}, *}$ and Takeshi Tabira ${ }^{\mathrm{b}, *}$ \\ ${ }^{a}$ Department of Immunology, Harbin Medical University, Harbin, People's Republic of China \\ ${ }^{\mathrm{b}}$ Department of Diagnosis, Prevention and Treatment of Dementia, Juntendo University, Hongo, Bunkyo-ku, \\ Tokyo, Japan
}

\begin{abstract}
Although NK cells are innate lymphocytes and have long been well known for their cytotoxic actions against tumor and virus infected cells, accumulating data indicate that they play an important immunoregulatory role in the pathogenesis of autoimmune diseases, such as MS and EAE. Especially, in recent years growing body of evidence suggest that NK cells have the potential to eliminate harmful self-reactive $\mathrm{T}$ cells and act as modulator of adaptive immunity. Here we review the recent advances in the research of NK cells related to EAE and MS, including general properties of NK cells, NK cells and EAE, and NK cells and MS, with emphasis on the mechanism of NK cell regulatory roles in EAE and MS.
\end{abstract}

Keywords: Natural killer cells, experimental autoimmune encephalomyelitis, multiple sclerosis, immunoregulation

\section{INTRODUCTION}

Multiple sclerosis (MS) and its animal model experimental autoimmune encephalomyelitis (EAE) have long been regarded as autoimmune diseases mediated by $\mathrm{CD}^{+}{ }^{+} \mathrm{T}$ cell immunity, but more recent works indicate that $\mathrm{CD}^{+} \mathrm{T}$ cells and $\mathrm{B}$ cells also play an important role in the disease development $[1,2]$. Now the key question in MS and EAE lies in what disrupts the $\mathrm{T}$ cell and $\mathrm{B}$ cell immunological tolerance against CNS antigens that are usually kept well secluded from

\footnotetext{
*Correspondence to: Dr. Wen Xu, Department of Immunology, Harbin Medical University, 157 BaoJian Road, NanGang District, Harbin 150086, People's Republic of China. Tel.: 8645186674566 ; E-mail: wenxu2006tokyo@yahoo.cn; or Dr. Takeshi Tabira, Department of Diagnosis, Prevention and Treatment of Dementia, Juntendo University, The 2nd Yaguchi Bldg. 3F, 2-11-5 Hongo, Bunkyoku, Tokyo 113-0033, Japan. Tel.:/Fax: 8136801 8332; E-mail: spfe6he9@mild.ocn.ne.jp.
}

the systemic immune system [3-5]. To clarify the immune regulation in autoimmune responses, much effort have been dedicated to investigate the role of adaptive regulatory $\mathrm{T}$ cells, including Foxp $3^{+} \mathrm{CD} 4^{+} \mathrm{T}$ cells [6], IL-10 producing Tr1 cells [7] and TGF- $\beta$ producing Th3 cells $[8,9]$. However, recent publications provide evidence that cells of the innate immune system have the potential to inhibit autoreactive $\mathrm{CD}^{+}{ }^{+} \mathrm{T}$ cells [10-13]. Especially, NK cells are emerging as key participants in the regulation of autoimmune diseases [10-15]. In this review, we focus on the latest advances in the research of the role of NK cells in the regulation of EAE and MS.

\section{GENERAL PROPERTIES OF NK CELLS}

NK cells are evolutionarily primitive lymphocytes that possess cytotoxic properties, classically directed against transformed and virus infected cells. Unlike 
$\mathrm{T}$ and $\mathrm{B}$ cells, NK cells are not antigen specific. NK cells usually constitute about $10 \%$ of the lymphocytes in human peripheral blood mononuclear cells (PBMC) [16].

NK cells lack a single unique genetic or phenotypic attribute but rather are identified by an amalgam of features both present and absent. Until recently, the identification of NK cells has relied on their lack of expression of $\mathrm{CD} 3$, combined with their expression of CD16 or CD56 in humans, of NK1.1 (CD161c) in certain mouse strains or of DX5 (CD49b) in all mouse strains [17].

$\mathrm{CD} 16$, a receptor for the Fc portion of $\mathrm{IgG}$ (Fc $\gamma \mathrm{RIII})$, is one of the first described NK cell-associated antigens, it enables cells to engage in antibody-dependent cellular cytotoxicity. Mature human NK cells are virtually all CD16 positive [18].

CD56 is another early described human NK cellassociated antigen. Although CD56 is commonly associated with NK-cell lineage, it is expressed on a wide variety of hematopoietic and nonhematopoietic cells, including T cells [19].

CD57 is a cell-surface glycoprotein that is expressed by approximately two thirds of human NK cells. CD57 is also expressed by a number of other cell types, including memory cytotoxic T cells [20]. The frequent expression of CD57 on T cells makes this antigen of relative little value in distinguishing them from NK cells.

As to mouse NK cell markers, the NK1.1 (CD161c, NKR-P1 C) antigen is the most widely used pan-NK cell marker in mice. Since its expression is restricted to CE, New Zealand Black, and C57BL/6-related strains, many commonly used strains do not express this antigen. In addition, like many other NK cell markers, NK1.1 is also expressed on a subset of T cells [21].

DX5, a novel monoclonal antibody (mAb), exhibits similar reactivity to anti-NK1.1 antibody but reacts with NK cells in all strains of mice tested, including NK1.1 negative strains [22].

CD122 (IL-2 R $\beta$-chain), which is constitutively expressed on NK cells and a subset of T cells, can also be used to identify NK cells [23].

Recently, the NKp46 molecule has been demonstrated to be the most specific and universal NK cell marker in mammals [24].

NK cell cytotoxicity is determined by the collective signaling of an array of inhibitory and stimulatory receptors on their surface $[25,26]$. NK cell inhibitory receptors, commonly referred to as killer inhibitory Ig-like receptors (KIRs), interact with classical and non-classical MHC class I molecules [26]. Hence, NK cells are kept in an inactivated state through contact with self MHC class I molecules expressed on healthy cells. Examples of KIRs include the Ly49 family of molecules (that bind classical MHC class I) [26], and NKG2A (that binds Qa-1, a non-classical MHC class I molecule expressed on activated T cells, B cells and dendritic cells) $[25,26]$. On the contrary, NK cell cytotoxicity is generally elicited by a distinct set of inducible molecules that have a weak homology with MHC class I and bind NK stimulatory receptors [26]. The main activating receptors constitutively expressed on all NK cells in peripheral blood are NKG2D and the natural cytotoxicity receptors (NCRs) NKp30 and NKp46, while NKp44 is inducible upon activation [27]. All of these activating receptors probably recognize molecules that are up-regulated upon cellular stress [26, 27].

NK cells, upon activation, mediate cytotoxicity via cell-to-cell contact-dependent pathways involving perforin/granzyme [28], Fas/Fas-ligand [29] and TRAIL/TRAIL-ligand interactions [30]. They also produce proinflammatory cytokines/chemokines, such as IFN- $\gamma$, TGF- $\beta$, GM-CSF and CCL5 [31]. Although NK cells have long been well known for their cytotoxic actions against tumor and virus infected cells, now accumulating evidence indicate that NK cells have the potential to eliminate harmful self-reactive $\mathrm{T}$ cells and act as a modulator of adaptive immunity [10-15].

The majority (around 95\%) of human NK cells in PBMC belong to the $\mathrm{CD} 56^{\mathrm{dim}} \mathrm{CD} 16^{+}$cytolytic NK subset [27]. These cells express homing markers for inflamed peripheral sites and carry perforin to rapidly mediate cytotoxicity [27]. The minor NK subset in blood (around 5\%) is $\mathrm{CD} 56^{\text {bright }} \mathrm{CD} 16^{+}$cells [27]. These NK cells lack perforin, but secrete large amounts of IFN- $\gamma$ and TNF- $\alpha$ upon activation. And they are superior to $\mathrm{CD} 56^{\mathrm{dim}} \mathrm{CD} 16^{+} \mathrm{NK}$ cells in the immune regulatory functions [27]. In addition, they express homing markers for secondary lymphoid organs, namely CCR7 and CD62 L [27]. Accordingly, NK cells harbored in secondary lymphoid organs are almost exclusively represented by this latter subset.

\section{THE REGULATORY ROLE OF NK CELLS IN EAE}

In 1997 our lab reported that treatment of $\mathrm{MOG}_{35-55}$ sensitized C57BL/6 mice with a depleting antibody specific for NK1.1 accelerated the onset and increased the severity of clinical EAE [32]. In parallel experiments, MOG specific $\mathrm{CD}^{+}{ }^{+} \mathrm{T}$ cell lines induced a more 
severe form of EAE in syngeneic hosts treated with an anti-NK1.1 antibody than in hosts treated with an isotype matched control antibody. Aggravation of EAE by $\mathrm{NK}$ cell deletion was also seen in $\beta 2$-microglobulin deficient mice, indicating that NK cells can play a regulatory role in a manner independent of $\mathrm{CD} 8^{+} \mathrm{T}$ cells or NK1.1 ${ }^{+} \mathrm{T}$ cells (NKT cells) [32]. We also found that NK cells depletion led to aggravated EAE in SJL/J mice, in which NKT cells are quantitatively and functionally deficient [33]. Supporting the mouse data, NK cells have been detected in the central nervous system of rats with EAE. When NK cells are depleted, the disease is aggravated, although the role of NK cells and NKT cells was not addressed separately [34].

It was reported that NK cells comprise up to $17 \%$ of CNS-infiltrating inflammatory cells in Lewis rats at the peak of disease [34]. In C57BL/6 mice, it was reported that $\mathrm{NK} 1.1^{+} \mathrm{CD}^{-}$cells account for $10-20 \%$ of the infiltrate in symptomatic mice immunized with $\mathrm{MOG}_{35-55}$ [35]. Both observations show that significant numbers of NK cells accumulate within the target organ during the acute stage of EAE. Studies with genetically engineered mice indicate that the accumulation of NK cells in the CNS is not a random event, but the consequence of a CX3CL1 (fractalkine) dependent pathway [35].

Huang et al. have reported that mice deficient for CX3CR1 (the fractalkine receptor) develop a more severe form of EAE [35]. Unlike their CX3CR $1^{+/-}$littermates, CX3CR $1^{-/-}$mice immunized with $\mathrm{MOG}_{35-55}$ exhibited a higher incidence of CNS hemorrhages and a higher mortality rate, and failed to recover function after they had reached the peak of EAE. Although the CX3CR1 ${ }^{-/-}$mice developed more severe manifestations of EAE, recall responses to $\mathrm{MOG}_{35-55}$ and the generation of encephalitogenic $\mathrm{T}$ cells in the peripheral lymphoid organs were not augmented in the mice. Analysis of spinal cord mononuclear cells from these mice revealed a selective absence of $\mathrm{NK} 1.1^{+} \mathrm{CD} 3^{+}$cells, which compose $10-20 \%$ of CNS infiltrates in wild-type CX3CR $1^{+/+}$or heterozygous CX3CR $1^{+/-}$ littermates. This finding leads the authors to speculate that the exacerbated disease in $\mathrm{CX} 3 \mathrm{CR} 1^{-/-}$mice was due to a failure of regulatory NK cells to enter the target organ. In support of this, the majority of CNS infiltrating NK cells in CX3CR $1^{+/-}$mice expressed CX3CR1, and treatment of $\mathrm{MOG}_{35}-55$-immunized $\mathrm{CX} 3 \mathrm{CR} 1^{+/-}$ mice with an anti-NK1.1 antibody resulted in EAE of comparable severity to the $\mathrm{CX} 3 \mathrm{CR} 1^{-/-}$mice littermates. Furthermore, soluble CX3CL1 was increased in the CNS during EAE, and protein extracts from
CNS tissues showed a chemotactic activity for wildtype NK cells [35]. Intriguingly, it has been reported that a reduced number of circulating $\mathrm{CX} 3 \mathrm{CR} 1^{+} \mathrm{NK}$ cells was detected in patients with MS [36].

Huang et al. further addressed that a defect of conventional NK cells, rather than NKT cells, is responsible for the phenotype of $\mathrm{CX} 3 \mathrm{CR} 1^{-/-}$ mice [35]. They showed that MOG-immunized

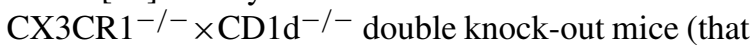
lack NKT cells) resemble $\mathrm{CX} 3 \mathrm{CR} 1^{-/-}$mice with regard to both the clinical course and histological features of EAE, whereas $\mathrm{CD}^{-1} \mathrm{~d}^{-/}$single knockout mice resemble wild-type controls. Moreover, the authors further investigated the extent of the NK cell defect in $\mathrm{CX} 3 \mathrm{CR}^{-/-}$mice and its bearing on the inflammation site outside of the CNS. Interestingly, NK cells accumulated at a normal frequency in the spleen and liver of CX3CR1 $1^{-/-}$mice infected with cytomegalovirus, suggesting that CX3CR1/CX3CL1 interactions are of particular importance for $\mathrm{NK}$ cell recruitment and/or survival in the CNS [35].

Collectively, all of above mentioned literatures indicated that NK cells play an important protective role in EAE, although it is still not clear whether protective regulatory functions are a global property of NK cells or they possess aggravating nature by a discrete subset.

\section{MECHANISM OF NK CELL REGULATORY ROLE IN EAE}

In 2005, we reported that NK cells could exert direct cytotoxic effect on syngeneic, myelin antigen-specific, encephalitogenic $\mathrm{T}$ cells [33]. In our experiments, first, in vivo NK cell depletion by anti-NK1.1 monoclonal antibody treatment enhanced EAE in SJL/J mice (Fig. 1). To investigate the mechanism, we cultured proteolipid protein (PLP) ${ }_{136-150}$ peptidespecific, encephalitogenic T cell lines, which were used as the NK cell target. Our results show that NK cells exert a direct cytotoxic effect on autoantigen-specific, encephalitogenic T cells (Fig. 2). Furthermore, cytotoxicity to PLP-specific, encephalitogenic T line cells was enhanced by using enriched NK cells as effector cells (Fig. 3). The cytotoxic effect of NK cells to ovalbumin-specific T line cells and ConA-stimulated T cells could also be detected with a lesser efficiency. Our studies indicate that NK cells play a regulatory role in EAE through killing of syngeneic T cells which include myelin antigen-specific, encephalitogenic T cells, and thus ameliorate EAE [33]. 


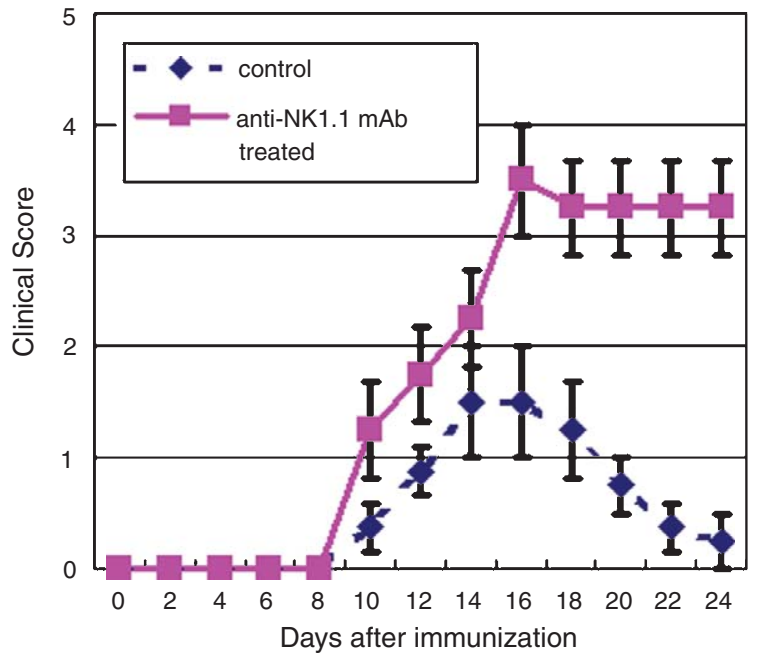

Fig. 1. NK cell depletion enhances EAE in SJL/J mice. Mice were immunized with $100 \mu \mathrm{g}$ of PLP $_{136-150}$ in complete Freund adjuvant. Mice were also injected intraperitoneally with $400 \mathrm{ng}$ of pertussis toxin (PT) shortly after and $48 \mathrm{~h}$ after immunization. Anti-NK1.1 mAb-treated group mice were injected with $500 \mu \mathrm{g}$ of anti-NK1.1 $\mathrm{mAb}$ (PK136) 1 day before and 14 days after immunization. Control mice were treated with PBS. Four mice in each group were used. This is representative of three experiments with silimar results.

As far as we know, this was the first observation that NK cells kill autologous encephalitogenic T cells. However, the observation was primitive, because we did not examine expression of either MHC class I, perforin, NKG2A or NKG2D. Furthermore, we did not observe whether PLP-specific T cells failed to transfer EAE after treatment with NK cells. Therefore, further studies were definitely needed to reach the conclusion. However, later studies by others support our speculation.

In 2006, Bielekova et al. reported that NK cells isolated from peripheral blood mononuclear cells of human donors kill activated autologous T cells following pre-stimulation with IL-12 [37]. In 2007 and 2008, it has also been reported that $\mathrm{T}$ cells could upregulate NKG2D ligands following activation and became susceptible to autologous NK cell-mediated cell lysis in vitro [38, 39].

Lu et al., in 2007, investigated some of the factors controlling the ability of NK cells to lyse activated $\mathrm{T}$ cells [40]. They found that $\mathrm{CD}^{+} \mathrm{T}$ cells genetically deficient in the non classical MHC class I molecule, Qa-1, underwent an accelerated rate of death when primed in immunocompetent hosts. Here, Qa1 is known as the molecule that interacts with the NK inhibitory receptor, NKG2A, and is normally upregulated during $\mathrm{T}$ cell activation. However, the Qa1 deficient $\mathrm{CD}^{+}{ }^{+} \mathrm{T}$ cells expanded and survived as wild-type $\mathrm{CD}^{+}{ }^{+} \mathrm{T}$ cells in perforin deficient or NKdepleted hosts. $\mathrm{CD} 4^{+} \mathrm{T}$ cells that express a mutant form of Qa-1, which is prohibitive of interactions with the NK inhibitory receptor, NKG2A, exhibited a
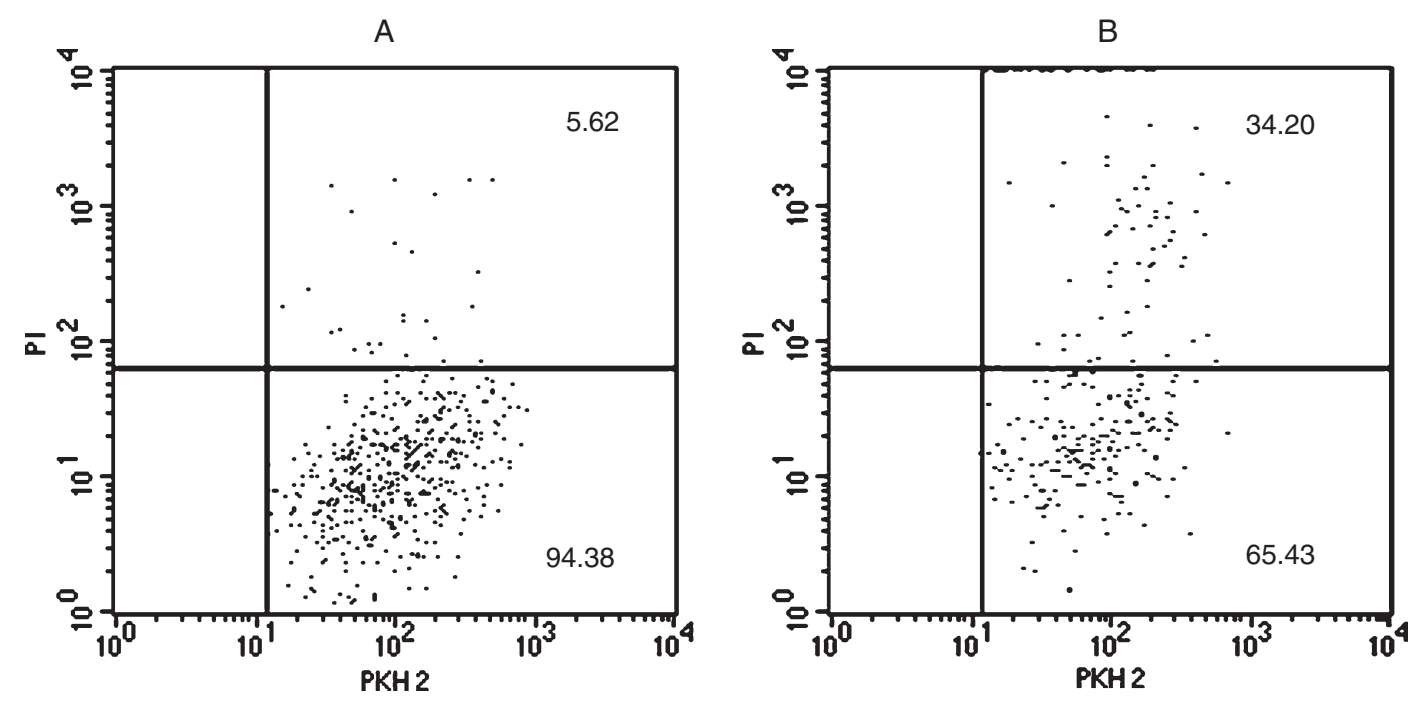

Fig. 2. NK cells exert direct cytotoxic effect on PLP-specific encephalitogenic T cell lines. The target T line cells were labeled with PKH 2 , then labeled target cells were incubated with nonlabeled naive mice spleen cells at ratio of $50: 1,100: 1,200: 1,400: 1$ (Effector: Target). After $4 \mathrm{~h}$ of incubation, cells were harvested and stained with PI. Dead target T cells were double positive for both PKH 2 and PI, while living target cells were only positive for PKH 2. (A) without effector cells; (B) with effector cells at the ratio of $200: 1$. One representative experiments out of three is shown. 


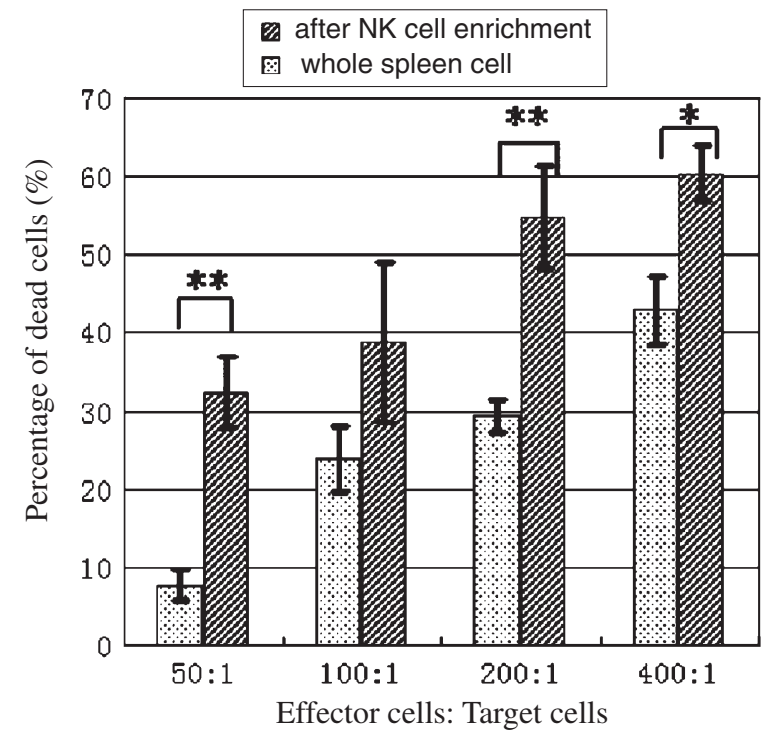

Fig. 3. Cytotoxicity to PLP-specific, encephalitogenic T line cells was enhanced by using enriched NK cells as effector cells. NK cells enrichment was done as following: splenic cells were incubated on a plastic culture dish, nonadherent cells were collected and incubated with anti-mouse CD19 Microbeads and anti-mouse CD5 Microbeads, then NK cells were negatively selected by passing through a MACS column. The purity of NK cells was examined by flow cytometry. Cytotoxic effect to PLP-specific, encephalitogenic T cells by using naive mice splenic NK cells and enriched NK cells as effector cells was examined and compared by using the same method as described in the legend to Fig. 2. The final results were calculated by subtracting the background and expressed as mean \pm S.E. of three samples at each $E: T$ ratio. ${ }^{*} P<0.05 ; * * P<0.01$.

similar phenotype. Furthermore, transfection of wildtype ovalbumin-specific $\mathrm{CD}^{+}{ }^{+} \mathrm{T}$ cells with lentivirus encoding Qa-1 improved their survival upon antigendriven expansion in syngeneic OVA-immunized mice. Collectively, these data suggest that upregulation of Qa-1 on $\mathrm{CD}^{+} \mathrm{T}$ cells during activation in vivo is protective against perforin mediated lysis by NKG2A expressing NK cells. With regard to EAE, the authors reported that MOG-specific, T cell receptor transgenic $\mathrm{CD} 4^{+} \mathrm{T}$ cells lose the ability to transfer EAE into Rag2 $2^{-/-}$hosts once they are backcrossed to a Qa1 deficient background. Nevertheless, these cells are able to induce disease in $\mathrm{Rag}^{-/-}$hosts that are either deficient in perforin or depleted of NK cells. Consistent with these findings, administration of an anti-Qa-1 antibody to MOG-sensitized wild-type mice during the preclinical phase significantly reduced the severity of EAE. However, the therapeutic effect of the anti-Qa-1 antibody was destroyed by co-administration of an NK cell depleting antibody [40]. In conclusion, encephalitogenic $\mathrm{CD}^{+} \mathrm{T}$ cells are suppressed by NK cells via a perforin dependent mechanism if they fail to upreg- ulate Qa-1 during in vivo priming. Conversely, high or constitutively expression of Qa-1 could, theoretically, favor the expansion and differentiation of autoreactive $\mathrm{T}$ cells in patients during relapses of autoimmune disease.

In summary, the majority of data on the mechanism of regulatory NK cells in EAE suggest that NK cells directly trigger the death of encephalitogenic $\mathrm{T}$ cells.

\section{NK CELLS AND MULTIPLE SCLEROSIS}

Indirect evidence that NK cells can play a protective role in autoimmunity is provided by the fact that naturally occurring mutations in genes that cause a defect in NK cells can predispose individuals towards autoimmune diseases [41-44].

However, actually it has long been controversial regarding the role of NK cells in MS. Most of studies reported that patients with MS have reduced numbers of circulating NK cells and/or functionally deficient NK cells [45-52]. With regard to the latter, NK cells isolated from MS patients were found to be inefficient at cytotoxic killing and production of IFN- $\gamma$ [45-48, $51,52]$. In a longitudinal study, NK cell functional activity fell in concert with the onset of clinical MS relapses but normalized during remission [53]. On the contrary, there are still some papers, although in the minority, reporting no differences, either quantitatively and qualitatively, between NK populations in MS patients versus healthy controls [54-57]. The reason for these controversial findings remains unclear. However, it is of note that in the above mentioned literatures, the criteria used to classify NK cells, the assays and protocols used to measure their functions and/or frequencies, and the patient populations studied differ widely among researchers.

More recently, protective roles for NK cells in patients with MS have been suggested [58]. Takahashi et al. reported that NK cells from patients in disease remission expressed high levels of Fas (CD95) and were classified as NK2 cells, distinguished by the secretion of Th2 cytokines, such as IL-5 and IL-13 $[58,59]$. They also reported that in vitro-induced NK2 cells inhibited the induction of Th1 cells, suggesting that NK2 cells in vivo may also prohibit autoimmune effector T cells development [59]. The type I and type 2 NK cells are supposed to be at the distinct stages of differentiation of NK cells from progenitor cells [60].

It is also reported that NK cells infiltrating in the CNS express neurotrophic factors that might contribute to the rescue of mechanically injured neurons, therefore NK cells may also constitute an important 
mechanism for neuronal protection in CNS inflammation [61].

Strong evidence for a role of regulatory NK cells in MS comes from data on daclizumab, a new humanized $\mathrm{mAb}$ against IL-2 receptor $\alpha$-chain [37]. In the phase II trial of daclizumab in relapsing remitting MS patients, Bielekova et al. have noticed that an expansion of CD56 $6^{\text {bright }}$ immunoregulatory $\mathrm{NK}$ cells and their increased perforin expression would highly correlate with the reduction of the disease activity. In fact, contrast enhanced lesions on brain MRI were significantly suppressed along with an expansion of circulating CD56 ${ }^{\text {bright }} \mathrm{NK}$ cells and contraction of $\mathrm{CD}^{+}{ }^{+}$and $\mathrm{CD}^{+} \mathrm{T}$ cells. Furthermore, NK cells isolated from patients during, but not before, daclizumab therapy were found to exhibit cytotoxicity towards autologous activated $\mathrm{T}$ cells, even without prestimulating NK cells with IL-12. These results raise a possibility that induced regulatory NK cells may have at least partially mediated daclizumab effects on MS.

In another study, an increase of CD56 ${ }^{\text {bright }} \mathrm{NK}$ cells was demonstrated in the blood of newly diagnosed patients with relapsing remitting MS who were started on interferon- $\beta$ treatment a few months prior to the study [62]. This work also support a role of induced regulatory $\mathrm{NK}$ cells in patients who respond to the immunomodulatory therapy.

It is also reported that the reduction of the clinical relapse rate during pregnancy was associated with an increase in the CD56 $6^{\text {bright }} \mathrm{NK}$ cell population, and a decrease in the CD56 ${ }^{\mathrm{dim}} \mathrm{NK}$ cell population [63].

In summary, the available data indicate that NK cells or some subsets of NK cells play a protective role in MS.

\section{CONCLUSION AND CLINICAL IMPLICATIONS}

For many years, T helper type 1 (Th1) cells were considered to be responsible for the pathogenesis of MS, however, current research is providing more and more evidence that other cell types are also involved, for example, Th17 cells, CD8 ${ }^{+} \mathrm{T}$ cells, B cells. An additional pathologic role can be assigned to the innate immune system; in particular, TLR-signaling is gaining increasing attention as well as dendritic cells, macrophages, mast cells and $\gamma \delta \mathrm{T}$ cells have been shown to exert deleterious effects. Apart from these pathogenic cell populations, regulatory cells are involved in the immunopathology of the disease; among them, regulatory $\mathrm{T}$ cells are vital for maintaining self-tolerance, and certain subsets of $\mathrm{CD}^{+} \mathrm{T}$ and B cells, NK and NKT cells have shown ameliorative effects on disease development[64]. A better understanding of the regulatory axis of autoimmune encephalomyelitis poses an important aim for the development of alternative therapeutic approaches, which do not aim at detrimental but beneficial immune function.

NK cells are now emerging as innate effectors able not only to exert mere innate immunity function, but also to critically tune adaptive immune response, including autoreactive $\mathrm{T}$ cell response.

In order to control the autoreactive, myelin antigen-specific, T lymphocyte aggression, selectively induction of NK cells regulatory properties may pave the way to new immunotherapeutic approaches for MS.

Furthermore, because NK cells change their phenotypes, numbers, and gene expression profile during disease course of MS, NK cells may also be utilized as surrogate marker for disease activity and treatment response.

\section{REFERENCES}

[1] Huseby E, Liggitt D, Brabb T, Schnabel B, Ohlen C, Goverman A. Pathogenic role for myelin-specific $\mathrm{CD}^{+} \mathrm{T}$ cells in a model for multiple sclerosis. J Exp Med. 2001; 194: 669-676.

[2] Skulina C, Schmidt S, Dornmair K, Babbe H, Roers A, Rajewsky K, Wekerle H, Hohlfeld R, Goebels N. Multiple sclerosis: brain-infiltrating $\mathrm{CD}^{+} \mathrm{T}$ cells persist as clonal expansions in the cerebrospinal fluid and blood. Proc Natl Acad Sci U S A. 2004; 101: 2428-2433.

[3] Goodnow C, Sprent J, Fazekas de St., Groth B, Vinuesa C. Cellular and genetic mechanism of self-tolerance and immunity. Nature. 2005; 435: 590-597.

[4] Kyewski B, Derbinski J. Self-representation is the thymus: an extended view. Nat Rev Immunol. 2004; 4: 688-698.

[5] Walker L, Abbas A. Keeping self-reactive. T cells at bay in the periphery. Nat Rev Immunol. 2002; 2: 11-19.

[6] Miyara M, Sakaguchi S. Natural regulatory T cells: mechanisms of suppression. Trends Mol Med. 2007; 13: 108-116.

[7] Roncarolo M, Gregori S, Battaglia M, Bacchetta R, Fleischhauer K, Levings M. Interleukin-10-secreting type. I regulatory T cells in rodents and humans. Immunol Rev. 2006; 212: 28-50.

[8] Awasthi A, Carrier Y, Peron JP, Bettelli E, Kamanaka M, Flavell RA, Kuchroo VK, Oukka M, Weiner HL. A dominant function for interleukin 27 in generating interleukin 10-producing anti-inflammatory T cells. Nat Immunol. 2007; 8: 1380-1389.

[9] Baecher-Allan C, Hafler D. Human regulatory T cells and their role in autoimmune disease. Immunol Rev. 2006; 212 : 203-216.

[10] Carrol M, Prodeus A. Linkages of innate and adaptive immunity. Curr Opin Immunol. 1998; 10: 36-40.

[11] Fearon D, Locksley R. The instructive role of innate immunity in the acquired immune response. Science. 1996; 272: 50-53.

[12] Medzhitov R, Janeway JC. Innate immunity: impact on the adaptive immune response. Curr Opin Immunol. 1997; 9: 4-9. 
[13] Shi F, Ljunggren H, Sarventnick N. Innate immunity and autoimmunity: from self-protection to self-destruction. Trends Immunol. 2001; 22: 97-101.

[14] Bendelac A, Fearon DT. Innate pathways that control acquired immunity. Curr Opin Immunol. 1997; 9: 1-3.

[15] Shi F, Van Kaer L. Reciptocal regulation between natural killer cells and autoreactive T cells. Nat Rev Immunol. 2006; 6: 751-760.

[16] Steinman L. Multiple sclerosis: a two-stage disease. Nat Immunol. 2001; 2: 762-764.

[17] Huntington ND, Vosshenrich CA, Di Santo JP. Developmental pathways that generate natural-killer-cell diversity in mice and humans. Nat Rev Immunol. 2007; 7(9): 703-714.

[18] Lanier LL, Ruitenberg JJ, Phillips JH. Functional and biochemical analysis of CD16 antigen on natural killer cells and granulocytes. J Immunol. 1988; 141: 3478-3485.

[19] Lanier LL, Le AM, Civin CI, Loken MR, Phillips JH. The relationship of CD16 (Leu-11) and Leu-19 (NKH-1) antigen expression on human peripheral blood NK cells and cytotoxic T lymphocytes. J Immunol. 1986; 136: 4480-4486.

[20] Tarazona R, DelaRosa O, Alonso C, Ostos B, Espejo J, Pena $\mathrm{J}$, Solana R. Increased expression of NK cell markers on T lymphocytes in aging and chronic activation of the immune system reflects the accumulation of effector/senescent $\mathrm{T}$ cells. Mech Ageing Dev. 2000; 121: 77-88.

[21] Vicari AP, Zlotnik A. Mouse. NK1.1 ${ }^{+}$T cells: a new family of T cells. Immunol Today. 1996; 17: 71-76.

[22] Arase H, Saito T, Phillips JH, Lanier LL. Cutting edge: the mouse NK cell-associated antigen recognized by DX5 monoclonal antibody is CD49b (alpha 2 integrin, very late antigen-2). J Immunol. 2001; 167(3): 1141-1144.

[23] Kouro T, Kumar V, Kincade PW. Relationships between early B- and NK-lineage lymphocyte precursors in bone marrow. Blood. 2002; 100(10): 3672-3680.

[24] Walzer T, Blery M, Chaix J, Fuseri N, Chasson L, Robbins SH, Jaeger S, Andre P, Gauthier L, Daniel L, Chemin K, Morel Y, Dalod M, Imbert J, Pierres M, Moretta A, Romagne F, Vivier E. Identification, activation, and selective in vivo ablation of mouse NK cells via NKp46. Proc Natl Acad Sci USA. 2007; 104(9): 3384-3389.

[25] Borrego F, Masilamani M, Marusina AI, Tang X, Coligan JE. The CD94/NKG2 family of receptors: from molecules and cells to clinical relevance. Immunol Res. 2006; 35: 263 278.

[26] Kirwan SE, Burshtyn DN. Regulation of natural killer cell activity. Curr Opin Immunol. 2007; 19: 46-54.

[27] Moretta A, Bottino C, Vitale M, Pende D, Cantoni C, Mingari MC, Biassoni R, Moretta L. Activating receptors and coreceptors involved in human natural killer cell-mediated cytolysis. Annu Rev Immunol. 2001; 19: 197-223.

[28] Warren H, Smyth M. NK cells and apoptosis. Immunol Cell Biol. 1999; 77: 64-75.

[29] Screpanti V, Wallin R, Grandien A, Ljunggren H. Impact of FASL-induced apoptosis in the elimination of tumor cells. Mol Immunol. 2005; 42: 495-499.

[30] Takeda K, Hayakawa Y, Smyth M, Kayagaki N, Yamaguchi N, Kakuta S, Iwakura Y, Yagita H, Okumura K. Involvement of tumor necrosis factor-related apoptosis-inducing ligand in surveillance of tumor metastasis by liver natural killer cells. Nat Med. 2001; 7: 94-100.

[31] Biron CA, Nguyen KB, pien GC, Cousens LP, Salazar-Mather TP. Natural killer cells in antiviral defense: function and regulation by innate cytokines. Annu Rev Immunol. 1999; 17: 189-220.
[32] Zhang B, Yamamura T, Kondo T, Fujiwara M, Tabira T. Regulation of experimental autoimmune encephalomyelitis by natural killer (NK) cells. J Exp Med. 1997; 186: 1677-1687.

[33] Xu W, Fazekas G, Hara H, Tabira T. Mechanism of natural killer (NK) cell regulatory role in experimental autoimmune encephalomyelitis. J Neuroimmunol. 2005; 163: 24-30.

[34] Matsumoto Y, Kohyama K, Aikawa Y, Shin T, Kawazoe Y, Suzuki Y, Tanuma N. Role of natural killer cells and TCR gamma delta T cells in acute autoimmune encephalomyelitis. Eur J Immunol. 1998; 28: 1681-1688.

[35] Huang D, Shi F, Jung S, Pien G, Wang J, Salazar-Mather T, He TT, Weaver JT, Ljunggren HG, Biron CA, Littman DR, Ransohoff RM. The neuronal chemokine CX3CR1/fractalkine selectively recruits NK cells that modify experimental autoimmune encephalomyelitis within the central nervous system. FASEB J. 2006; 20: 896-905.

[36] Infante-Duarte C, Weber A, Kratschmar J, Prozorovski T, Pikol S, Hamann I, Bellmann-Strobl J, Aktas O, Dorr J, Wuerfel J, Sturzebecher CS, Zipp F. Frequency of blood CX3CR1-positive natural killer cells correlates with disease activity in multiple sclerosis. FASEB J. 2005; 19: 1902-1904.

[37] Bielekova B, Catalfamo M, Reichert-Scrivner S, Packer A, Cerna M, Waldmann TA, McFarland H, Henkart PA, Martin R. Regulatory CD56(bright) natural killer cells mediate immunomodulatory effects of IL-12R $\alpha$-targeted therapy (daclizumab) in multiple sclerosis. Proc Natl Acad Sci U S A. 2006; 103: 5941-5946.

[38] Cerboni C, Zingoni A, Cippitelli M, Piccoli M, Frati L, Santoni A. Antigen-activated human T lymphocytes express cell-surface NKG2D ligands via an ATM/ATR-dependent mechanism and become susceptible to autologous NK-cell lysis. Blood. 2007; 110: 606-615.

[39] Roy S, Barnes PF, Garg A, Wu S, Cosman D, Vankayalapati R. NK cells lyse T regulatory cells that expand in response to an intracellular pathogen. J immunol. 2008; 180: 1729-1736.

[40] Lu L, Ikizawa K, Hu D, Werneck MB, Wucherpfenning KW, Cantor $\mathrm{H}$. Regulation of activated $\mathrm{CD}^{+}{ }^{+} \mathrm{T}$ cells by NK cells via the Qa-1-NKG2A inhibitory pathway. Immunity. 2007; 26: 593-604.

[41] Gilmour KC, Fujii H, Cranston T, Davies EG, Kinnon $\mathrm{C}$, Gaspar HB. Defective expression of the interleukin2/interleukin-15 receptor beta subunit leads to a natural killer cell-deficient form of severe combined immunodeficiency. Blood. 2001; 98: 877-879.

[42] Biron CA, Byron KS, Sullivan JL. Severe herpes virus infections in an adolescent without natural killer cells. N Engl Med. 1989; 320: 1731-1735

[43] Zimmer J, Bausinger H, de la Salle H. Autoimmunity mediated by innate immune effector cells. Trends Immunol. 2001; 22: 300-301.

[44] Moins-Teisserenc HT, Gadola SD, Cella M, Dunbar PR, Exley A, Blake N, Baykal C, Lambert J, Bigliardi P, Willemsen M, Jones M, Buechner S, Colonna M, Gross WL, Cerundolo V. Association of a syndrome resembling Wegener's granulomatosis with low surface expression of HLA class I molecules. Lancet. 1999; 354: 1598-1563.

[45] Benczur M, Petranyl GG, Palffy G, Varga M, Talas M, Kotsy B, Foldes I, Hollan SR. Dysfunction of natural killer cells in multiple sclerosis: a possible pathogenetic factor. Clin Exp Immunol. 1980; 39: 657-662.

[46] Braakman E, van Tunen A, Meager A, Lucas CJ. Natural cytotoxic activity in multiple sclerosis patients: defects in IL2/interferon-gamma-regulatory circuit. Clin Exp Immunol. 1986; 66: 285-294. 
[47] Hirsch RL, Johnson KP. Natural killer cell activity in multiple sclerosis patients treated with recombinant interferon-alpha 2. Clin Immunol Immunopathol. 1985; 37: 236-244.

[48] Kastrukoff LF, Morgan NG, Zecchini D, White R, Paty DW. A role for natural killer cells in the immunopathogenesis of multiple sclerosis. J Neuroimmunol. 1998; 86: 123-133.

[49] Kreuzfelder E, Shen G, Bittor M, Scheiermann N, Thraenhart O, Seidel D, Grosse-Wilde H. Enumeration of T, B and natural killer peripheral blood cells of patients with multiple sclerosis and controls. Eur Neurol. 1992; 32: 190-194.

[50] Munschauer FE, Hartrich LA, Stewart CC, Jacobs L. Circulating natural killer cells but not cytotoxic T lymphocytes are reduced in patients with active relapsing multiple sclerosis and little clinical disability as compared to controls. J Neuroimmunol. 1995; 62: 177-181

[51] Uchida A, Maida EM, Lenzhofer R, Micksche M. Natural killer cell activity in patients with multiple sclerosis: interferon and plasmapheresis. Immunobiology. 1982; 160: 392-402.

[52] Vranes Z, Poljakovic Z, Marusic M. Natural killer cell number and activity in multiple sclerosis. J Neurol Sci. 1989; 04: 115123.

[53] Kastrukoff LF, Lau A, Wee R, Zecchini D, White R, Paty DW. Clinical relapses of multiple sclerosis are associated with 'novel' valleys in natural killer cell functional activity. $\mathrm{J}$ Neuroimmunol. 2003; 145: 103-114.

[54] Hauser SL, Ault KA, Levin MJ, Garovoy MR, Weiner MR. Natural killer cell activity in multiple sclerosis. J Immunol. 1981; 127: 1114-1117.

[55] Rauch HC, Montgomery IN, Kaplan. J. Natural killer cell activity in multiple sclerosis and myasthenia gravis. Immunol Invest. 1985; 14: 427-434.

[56] Rice GP, Casali P, Merigan TC, Oldstone MB. Natural killer cell activity in patients with multiple sclerosis given alpha interferon. Ann Neurol. 1983; 14: 333-338.
[57] Santoli D, Hall W, Kastrukoff L, Lisak RP, Perussia B, Trinchieri G, Koprowski H. Cytotoxic activity and interferon production by lymphocytes from patients with multiple sclerosis. J Immunol. 1981; 126: 1274-1278.

[58] Takahashi K, Aranami T, Endoh M, Miyake S, Yamamura T. The regulatory role of natural killer cells in multiple sclerosis. Brain. 2004; 127: 1917-1927.

[59] Takahashi K, Miyake S, Kondo T, Terao K, Hatakenaka M, Hashimoto S, Yamamura T. Natural killer type 2 bias in remission of multiple sclerosis. J Clin Invest. 2001; 107: R23-R29.

[60] Loza MJ, Zamai L, Azzoni L, Rosati E, Perussia B. Expression of type 1 (interferon gamma) and type 2 (interleukin-13, interleukin-5) cytokines at distinct stages of natural killer cell differentiation from progenitor cells. Blood. 2002; 99: 1273-1281.

[61] Hammarberg H, Lidman O, Lundberg C, Eltayeb SY, Gielen AW, Muhallab S, Svenningsson A, Linda H, van Der Meide PH, Cullheim S, Olsson T, Piehl F. Neuroprotection by encephalomyelitis: rescue of mechanically injured neurons and neurotrophin production by CNS-infiltrating $\mathrm{T}$ and natural killer cells. J Neurosci. 2000; 20(14): 5283-5291.

[62] Saraste M, Irjala H, Airas L. Expansion of CD56bright natural killer cells in the peripheral blood of multiple sclerosis patients treated with interferon-beta. Neurol Sci. 2007; 28: 121-126.

[63] Airas L, Saraste M, Rinta S, Elovaara I, Huang YH, Wiendl H. Immunoregulatory factors in multiple sclerosis patients during and after pregnancy: relevance of natural killer cells. Clin Exp Immunol. 2008; 151: 235-243.

[64] Gandhi R, Laroni A, Weiner HL. Role of the innate immune system in the pathogenesis of multiple sclerosis. J Neuroimmunol. 2010; 221(1-2): 7-14. 